Revista de Ciencias Sociales - Número 62 (2013) - Páginas 13-37

Algunas reflexiones en torno a la ética de la profesión jurídica...

\title{
ALGUNAS REFLEXIONES EN TORNO A LA ÉTICA DE LA PROFESIÓN JURÍDICA A PROPÓSITO DEL NUEVO CÓDIGO DE ÉTICA DEL COLEGIO DE ABOGADOS DE CHILE*
}

\author{
SOME REFLECTIONS ON LEGAL ETHICS \\ ON OCCASION OF THE NEW CODE \\ OF ETHICS OF THE CHILEAN BAR
}

JAVIER GALLEGO SAADE**

Universidad de Chile / Universidad Diego Portales

javierg.saade@gmail.com

\section{Resumen}

El trabajo ofrece una introducción a los principios y dilemas que es importante reconocer al aproximarse a la ética de la profesión jurídica, entendida como una forma de ética práctica. Se desarrolla parte de la discusión académica comparada sobre la naturaleza de la moral propia de la profesión de abogado, y luego se intentan reconocer ciertos principios generales recogidos

* Este trabajo se basa en los capítulos primero y tercero de la memoria de licenciatura del autor, revisada por el profesor Antonio Bascuñán Rodríguez.

* Egresado de Derecho, Universidad de Chile. Ayudante del Departamento de Ciencias del Derecho y del Departamento de Ciencias Penales de la Universidad de Chile, y del Departamento de Teoría del Derecho de la Universidad Diego Portales. Artículo recibido el 21 de enero de 2013 y aceptado el 19 de marzo de 2013.

Revista de Ciencias Sociales - Número 62 (2013) - Universidad de Valparáíso - ISSN 0716-7725-Valparaíso, Chile 
en el nuevo código de ética del Colegio de Abogados, promulgado en 2011, así como ciertas tensiones en torno a la concepción del abogado que se reflejan y reproducen en esta regulación, en particular en el contexto del proceso penal chileno.

\section{Palabras claves}

Ética profesional, profesión jurídica, concepciones de la abogacía, código de ética.

\section{Abstract}

The paper offers an introduction to both the principles and problems that is important to recognize when approaching to the discipline of legal ethics, here treated as part of practical ethics. Part of a foreign academic discussion on the nature of the morality of lawyering is presented here. Then an attempt is made to recognize certain general principles in the norms of the new code of ethics of the Chilean Bar, promulgated in 2011, as well as certain tensions around the conception of lawyering in the same body of rules, in particular in the context of the Chilean criminal procedure.

\section{Keywords}

Legal ethics, legal profession, conceptions of advocacy, code of ethics.

$$
\begin{array}{r}
\text { "So you want to do good. Don't we all? But } \\
\text { when you become a lawyer, you have to define } \\
\text { good differently than you did before. As a lawyer you } \\
\text { are someone else's representative. You are acting on their } \\
\text { behalf. You're their spokesperson. You may not like the term, } \\
\text { but you're their mouthpiece. You are they, only you are better } \\
\text { educated and more articulated. So doing good often means doing good } \\
\text { specifically for your client, not for the world at large, and certainly } \\
\text { not for yourself". }
\end{array}
$$

Alan Dershowitz ${ }^{1}$

1. DERSHOWITZ, Alan: Letters to a young lawyer, Basic Books, 2001. Pág. 41.

Facultad de Derecho y Ciencias Sociales - Universidad de Valparaíso - Chile 


\section{Introducción}

Este es un trabajo sobre ética práctica o aplicada. Aunque no tenemos demasiado espacio para desarrollar con profundidad lo que ello significa, es necesario clarificar lo que será en lo sucesivo nuestro objeto de discusión. Para dar cuenta del lugar en que se sitúa la presente investigación convengamos por tanto lo siguiente: nos situamos en el espectro de discusión de la ética, que reconoce, en tanto disciplina filosófica, fases de desarrollo de un argumento propio de dicho ámbito. Así, autores como Ricardo Maliandi ${ }^{2}$, consideran que la reflexión moral comienza en una primera instancia particularmente abstracta, en la que se reconoce un problema de difícil resolución, que probablemente supone evaluar el rendimiento de algún criterio de rectitud (por ello decimos que involucra preguntas del tipo "¿qué es correcto hacer?”). En una segunda instancia se invoca algún aparato conceptual o teoría con algún grado de sofisticación, por la cual se toma partido para resolver el dilema o responder la pregunta. Entre estas teorías se encuentran aproximaciones deontológicas, utilitaristas, neo-contractualistas o bien otras de naturaleza escéptica o relativista. Cuando el desarrollo teórico en abstracto debe servir como criterio para tomar una decisión, la teoría ética encuentra aplicación práctica, en el sentido de que sus formulaciones admiten configurar una guía concreta para la acción o la decisión.

Actualmente los ámbitos en que la ética admite aplicación práctica se han vuelto fácilmente reconocibles o identificables, y entonces podemos afirmar que la ética aplicada ha adquirido algún grado de especificidad relativa al ámbito en que el ejercicio de razón práctica se encuentra con algunos problemas y con la necesidad de adoptar decisiones difíciles. Entre estas disciplinas encontramos la bioética, la ética medioambiental, la ética del mundo animal no humano, la ética de los medios de comunicación, la ética de los negocios, la ecoética, y la ética profesional. El presente es un trabajo sobre ética profesional.

2. MALIANDI, Ricardo: Ética, conceptos y problemas, Buenos Aires, Biblios, 2004. Págs. 45-77.

Revista de Ciencias Sociales - Número 62 (2013) - Universidad de Valparáíso - ISSN 0716-7725-Valparáiso, Chile 
La ética profesional también encuentra tantas subdivisiones como profesiones puedan existir y reclamen o requieran de una suerte de autogobierno y control institucional. La ética de las profesiones, y los cuerpos de reglas que condensan el set de normas de comportamiento y valores que se espera rijan el ejercicio de la profesión, representan la manifestación de una organización que reclama y concreta un ideal de auto-regulación de sus miembros. La profesión jurídica, siendo una de las más antiguas, mantiene desde hace bastante tiempo esta pretensión y este ideal.

En Chile la ética de la profesión jurídica no es relevante. Entre nosotros es evidente el deficitario tratamiento que recibe, tanto en la dimensión académica como en la esfera pública, la discusión sobre los fundamentos de la profesión jurídica, en términos del reconocimiento de los principios que la gobiernan, y los ideales que dicha profesión debería encarnar. La adhesión al Colegio de Abogados (entidad que representa a la profesión jurídica en Chile y a quienes la ejercen) no es obligatoria, en el sentido de que no es una exigencia para el ejercicio de la profesión jurídica, y por lo tanto tampoco lo es el seguimiento de las normas de comportamiento del código de ética profesional ${ }^{3}$. La

3. Esto responde a lo siguiente: como se sabe, en Chile la fiscalización del ejercicio profesional estaba antes a cargo de los colegios profesionales, en la constitución de 1925 establecidos como personas jurídicas de derecho público. En el caso de la profesión jurídica ésta se encontraba sometida al Colegio de Abogados, fundado el mismo 1925. El ideal de autorregulación absoluto se veía en un amplio sentido satisfecho por cuanto estaba establecido como requisito para el ejercicio de la profesión el sometimiento a las normas dictadas por los mismos profesionales. Este requisito permanece vigente hasta la dictación del DL 3.621 de 1981 que lo elimina y transforma los colegios profesionales en asociaciones gremiales. El art.19 No 16 eleva al rango constitucional esta degradación prohibiendo la exigencia de afiliación para el ejercicio de la profesión. Luego esta misma norma será objeto de reforma por la ley 20.050 que agregará un párrafo a su cuarto inciso facultando a los colegios profesionales para conocer de las reclamaciones relativas a la conducta ética de sus miembros. Con esto se produce una interesante anomalía muy bien notada por Pablo Fuenzalida: del hecho de que el desempeño del abogado sigue estando mediado enteramente por el derecho privado, interviniendo el derecho público solamente en el proceso de otorgamiento de personalidad jurídica al colegio, luego no existiendo colegiatura obligatoria y por último habiéndosele otorgado la facultad mencionada al colegio, se sigue la existencia (hasta la creación de tribunales especiales dedicados a la ejecución de las normas

Facultad de Derecho y Ciencias Sociales - Universidad de Valparaíso - Chile 
institución mencionada y algunos representantes de la dimensión académica manifiestan en la actualidad la necesidad de un cambio radical en este diseño y entonces una expansión de los ideales y valores de la profesión, por medio de la obligatoria sujeción de sus profesionales a las pautas de conducta universales.

El paso más significativo que se ha dado en esa vía es la dictación de un nuevo código de ética, que deja sin vigencia el código promulgado por el colegio de abogados en 1948. Este nuevo código, del año 2011, expande ámbitos de regulación que quedaban cubiertos por el código anterior, y en otros casos tematiza ciertas materias de las que la ética profesional chilena no se había preocupado hasta ahora. Entre los representantes de esta reforma existe un consenso en el sentido de que el nuevo código incurre en mínimas presuposiciones respecto del "ideal de abogado" subyacente a la regulación de ética profesional. Se asume por lo tanto la expansión del ejercicio de la profesión, y con ello la aparición de nuevos y complejos problemas en su ejercicio.

El nuevo código (en adelante, CEP) dividido en cinco secciones, regula extensamente los deberes del abogado para con su cliente en lo que respecta al nivel de empeño con que debe asumir el encargo, la lealtad debida en el caso de un eventual conflicto de intereses, el cumplimiento del deber de mantener secreto profesional y los deberes de contenido patrimonial. Regula además la relación del abogado con los medios de comunicación y con terceros en general ajenos al cliente. Si bien no hay secciones específicas relativas a la organización de los profesionales en estudios jurídicos, el artículo 11 hace extensiva toda referencia a los abogados también a los estudios de abogados. Además de las cinco secciones lleva un título preliminar cuyas reglas consagran principios generales de la profesión.

Este trabajo persigue reproducir parte de la discusión anglonorteamericana en torno a la pregunta por el estatus de la ética de la

éticas codificadas, cuestión que introduce como posibilidad la reforma a las normas de ética profesional chilenas de 2011) de dos ordenamientos paralelos: el de los abogados colegiados, sometidos al organismo en cuestión, y el de los abogados no colegiados, sometidos a la jurisdicción ordinaria. Sobre esto FUENZALIDA, Pablo: "Notas sobre la jurisdicción ética de los colegios profesionales", Doctrina MJD 200, 2008 (disponible en: www.microjuris.cl).

Revista de Ciencias Sociales - Número 62 (2013) - Universidad de Valparáíso - ISSN 0716-7725-Valparáiso, Chile 
profesión jurídica, y el estatus de las reglas codificadas de ética profesional. Los principios del título preliminar del CEP tienen que comenzar a hacerse prácticos, de modo de develar los problemas interesantes que pueden manifestarse en la aplicación de las reglas. Notaremos que de alguna manera cualquier problema se reconduce en definitiva a una tensión entre dos concepciones de la función del abogado, cuestión que recibe tratamiento al final.

\section{La naturaleza de la moral de los abogados}

El desarrollo de los problemas que en su aplicación encuentra el cuerpo de normas que contiene el CEP requiere de modo previo una respuesta a al menos dos preguntas. La primera, ¿cuál es la naturaleza de la moral propia de los abogados? Y la segunda ¿cuál es la naturaleza de las normas morales institucionalizadas dirigidas, en tanto pautas de conducta, a abogados?

El filósofo Bernard Williams planteó una aproximación a la primera pregunta (sobre la particularidad de la moral de abogados) que nos permite introducir una discusión que en algunos foros ya se considera clásica (y algo superada). Una de las tesis fundamentales sobre las que descansa su intento de proveer una respuesta a la pregunta insiste en que la ética profesional ("moral profesional" en el texto) ${ }^{4}$ no consiste simplemente en una moral diferente y que los profesionales no son solamente un grupo separado de individuos, porque por un lado ocurre que el ejercicio de la profesión en cuestión (o su existencia como tal) suele ser moralmente aceptada por los miembros de la comunidad, y por otro los profesionales se ven a sí mismos, después de todo, como miembros de dicha comunidad 5 . Esto plantea la siguiente cuestión: debe

4. Williams utiliza el concepto profesional morality. Aquí usaremos el concepto 'ética profesional'. En el texto de Williams se habla de moral profesional en sentido amplio, pero también en particular respecto de las normas que rigen la profesión de abogado, por esto el hecho de optar por el uso de dicho concepto parece responder al intento de hacer las consideraciones aplicables a un amplio espectro de profesiones, y luego en particular a la profesión de abogado.

5. WILLIAMS, Bernard: "Professional morality and its dispositions". En, del mismo: Making sense of humanity and other philosophical papers, Cambridge University Press, 1995. Pág. 193.

Facultad de Derecho y Ciencias Sociales - Universidad de Valparaíso - Chile 
existir una justificación del ejercicio de la profesión que sea aceptable en los términos de la moral tradicional, puesto que el ejercicio de la profesión no es desvinculable de los estándares evaluativos que tienen validez al interior de la comunidad, de modo tal que si la moral profesional no es asimilable en algún sentido a la moral tradicional, entonces no es sino otra forma de moral ${ }^{6}$. Puede ser el caso que se entienda a la moral profesional como un subgrupo de la moral tradicional ${ }^{7}$, pero ciertamente existen divergencias, que surgen del hecho

6. Ibídem.

7. Aquí el punto es el status de la ética profesional como ética práctica. La literatura especializada de ética de profesión jurídica ha evadido por lo general la analogía más útil con aquella disciplina de mayor reconocimiento en la dimensión de la ética práctica: la Bioética. Por otro lado, en una publicación reciente del "Centro de Estudios de Ética Aplicada” de la Universidad de Chile: Ética Aplicada. Perspectivas de responsabilidad para la sociedad civil en un mundo globalizado, Editorial Universitaria, Santiago, 2009, editada por Raúl Villarroel, en la cual se introducen fundamentos y explicaciones básicas sobre el rol de la ética aplicada y su diferencia con la meta-ética y se desarrollan perspectivas contemporáneas sobre ámbitos de la ética práctica que incluyen la bioética, ética de los negocios y del medioambiente, se excluye el análisis de la ética de las profesiones en general. Siguiendo a Peter Singer en lo relativo a la ética práctica en general, diríamos que la plausibilidad de la "practicidad" de la ética, y de que sea posible evitar tratar problemas éticos como manifestaciones de un debate mayor en el que simplemente se ofrecen construcciones teóricas sofisticadas, depende de la posibilidad un razonamiento ético. $\mathrm{Al}$ asumir esta posibilidad se asume al mismo tiempo la necesidad de un punto de vista universal para plantear dilemas éticos. Singer considera que el punto mínimo o el argumento mininamente plausible que muestra a la ética como un escenario donde se discuten posiciones sobre la base de razones desde una perspectiva universal es el utilitarismo. Desde ese punto de partida se deben ofrecer razones o argumentos para avanzar si es el caso que se desea rechazar un punto de partida mínimamente utilitarista. SINGER, Peter: Practical Ethics, Second Edition, Cambridge University Press, 1993. Págs. 1-15. La ética de la profesión jurídica incluye valores que la filosofía del derecho ha desarrollado de modo acabado, por lo que en su proceso de desarrollo normativo (formulación de reglas) se puede decir que ha superado la brecha mínima del utilitarismo. Los comentaristas suelen vincular esta forma de ética práctica a un fundamento meta-ético deontológico estándar. Sobre aproximaciones de meta-ética importantes (que incluyen: consecuencialismo utilitarista, ética deontológica y ética de la virtud) desde el punto de vista metodológico para el análisis de la ética de la profesión jurídica, véase (comentando y reproduciendo un trabajo de los autores David Luban y Deborah Rhode) EVANS,

Revista de Ciencias Sociales - Número 62 (2013) - Universidad de Valparáíso - ISSN 0716-7725-Valparaíso, Chile 
de que la verificación del espectro de validez de las normas morales que interesan se encuentra supeditada a la descripción de la conducta relevante. Bajo cierta descripción, un acto se realiza cubierto por el contexto formal de la profesión y resulta ser por tanto moralmente permisible, y bajo otra descripción más bien impermisible. La pregunta es ¿̇on estas divergencias entre la dimensión profesional y la noprofesional reducibles puramente a la descripción que favorece una u otra evaluación (moral)? Esta parece una pregunta que puede ser respondida por el propio profesional que está situado en una mejor posición para ello, puesto que desde su perspectiva es posible vislumbrar y comprender el cruce de la brecha desde la moral cotidiana hacia la moral profesional, a cuyos estándares se somete el sujeto que (libremente) decide vincularse a una profesión. Entonces la pregunta es ¿̇e qué modo se hacen apreciables las divergencias (entre la moral cotidiana y la profesional) luego de cruzar dicha brecha? Una posibilidad, que comenta Williams, es la de la adaptación por medio del entrenamiento profesional, que modifica la tendencia a rechazar, desde el punto de vista de la validez de disposiciones morales cotidianas, ciertos actos que expresan disposiciones profesionales ${ }^{8}$. La otra posibilidad es la del escenario opuesto, en el que las disposiciones cotidianas del sujeto no se ven modificadas pues el entrenamiento profesional no las modifica para que ello resulte así. Si es éste el caso entonces tenemos un profesional que se ve enfrentado a constantes conflictos en el ejercicio de su profesión, donde se confrontan los valores morales cotidianos que reconoce, con los actos propios de la profesión que de vez en cuando parecen contravenirlos. Esto último da pie para una tercera posibilidad, en virtud de la cual se sostiene que aquellos que eligen dedicarse al ejercicio de la profesión en cuestión, carecen de un sentimiento de vinculación a valores morales tradicionales ${ }^{9}$, aunque

Adrian: Assessing Lawyers' Ethics. A practitioners' guide, Cambridge University Press, New York, 2011. Págs. 67-70. Sobre esto también MORGAN, Thomas, ROTUNDA, Ronald, (eds.) Problems and materials on professional responsibility, Sixth edition, The foundation press Inc., New York, 1955. Págs. 20-22.

8. $\quad$ WILLIAMS, ob. cit., pág. 196.

9. Ídem.

Facultad de Derecho y Ciencias Sociales - Universidad de Valparaíso - Chile 
no carecen, ciertamente, de la capacidad para discriminar o distinguir entre actos profesionales y no-profesionales. Lo que ocurre si es éste el caso es que, a pesar de que los sujetos muestren alguna capacidad de compromiso con valores cotidianos a-profesionales, el hecho de que sea más bien una cuestión de orden general (es decir, una capacidad que pueden hacer rendir en cualquier otro contexto) muestra que los límites que el contexto profesional puede marcar son más bien difusos ${ }^{10}$. Por esta razón el entrenamiento profesional tiende, de modo poco sorprendente, a la primera opción, es decir, a la adaptación profesional. Ahora bien, en este proceso de entrenamiento puede ocurrir que se exalte el sentimiento de respeto por la profesión, lo que su vez puede producir una mistificación de la dignidad propia de la profesión ${ }^{11}$. Según Williams, para el caso de la profesión jurídica, se requiere que la educación que reciben quienes se entrenan para ejercerla produzca "ciertos anticuerpos contra la absorción de una concepción mistificada de la dignidad de la profesión [jurídica]"12. Aquí vuelven a jugar su rol las disposiciones morales propias de la profesión jurídica. Éstas —reconoce Williams — al igual que las disposiciones a seguir estándares éticos generales, se comprenden mejor si se pone la atención en el aparato psicológico del que está provisto el individuo a la hora de proponerse la vinculación a estándares éticos. Claro está, la manera en que la ética práctica revela su capacidad de rendimiento es a través de su codificación en cuerpos de normas (códigos de ética). El interés de Williams en este punto es trazar una diferencia no siempre observada entre las disposiciones de un profesional y las normas que se le exige seguir codificadas en cuerpos de normas denominados códigos de ética. Naturalmente, esta cuestión es crucial para nuestro análisis introductorio, y algo de ello pretendemos decir en la sección

10. Ibíd., pág. 197.

11. Ibíd., pág. 198.

12. Ibíd., pág. 199. Sobre educación jurídica y la formación de una concepción de la profesión jurídica, y la incidencia de ello en la ética legal KAUFMAN, Andrew: "Law and ethics". En: The Hastings Center Report, Vol. 7, N 6, 1977. Págs. 7-8.

Revista de Ciencias Sociales - Número 62 (2013) - Universidad de Valparáíso - ISSN 0716-7725-Valparaíso, Chile 
subsiguiente, pero antes de la pregunta por la juridificación o institucionalización de las normas morales la meta-reflexión sobre la ética de la profesión jurídica debe ser desarrollada. Williams nos permite introducirnos de modo muy apropiado a los objetivos de este trabajo, puesto que enfatiza de modo correcto la diferencia entre las disposiciones morales del abogado y las reglas éticas a la que se espera conforme su comportamiento en el contexto de un proceso penal (para mencionar el objeto específico de este trabajo). Resulta obvio que las primeras trascienden a las segundas, y que es posible discutir respecto de la naturaleza de los valores que se reconocen al hacer referencia a las disposiciones, lo que nos conduce a una pregunta antes que por el curso de acción concreto que ha de adoptar el abogado, por lo que el abogado 'debe ser'13. Pero todavía más, concluye en su artículo que la relevancia de la distinción entre disposiciones y reglas pasa también por reconocer la importancia de pensar la profesión jurídica en términos racionales e ideales, lo que quiere decir que al momento de ofrecer una reconstrucción racional de las disposiciones de ética profesional necesariamente entran a jugar un rol los principios fundantes y los valores que proyecta la profesión y la dotan de su particular dignidad.

Ahora bien, la pregunta sobre si existe algo así como una auténtica "moral de los abogados", o si es posible para los abogados acceder a un conjunto de valores morales propios de su profesión suele replantearse de un modo algo sugerente como la pregunta ¿puede un abogado al mismo tiempo ser una buena persona?

Considerando que ya contamos con algún aparato conceptual analítico provisto por la aproximación a la pregunta en cuestión (a la cualidad de la pregunta) por parte de Williams, referido a las profesiones en general, ahora podemos reproducir parte del fructífero debate - al menos en el foro académico angloamericano- que tuvo lugar durante los años setenta y ochenta, referido a la moral específica de la profesión jurídica.

Con cierta seguridad podemos afirmar que dicho debate se inaugura con el influyente artículo de Richard Wasserstrom, Lawyers

13. WILLIAMS, ob.cit., pág. 200.

Facultad de Derecho y Ciencias Sociales - Universidad de Valparaíso - Chile 
as professionals: some moral issues ${ }^{14}$. En dicho trabajo, el autor se propone enfrentar al menos dos críticas recurrentes a la figura del abogado, en primer lugar, respecto de su relación con el mundo, respecto de la cual se alega que la profesión le permite al abogado asilarse en la relación con su cliente y entonces comportarse de modo sistemáticamente amoral o bien ocasionalmente de modo inmoral. Respecto de su relación con el cliente, se cuestiona el trato impersonal y paternalista que le da a éste ${ }^{15}$. Sobre la marcha parece ser que la primera crítica es su principal preocupación (y la nuestra también al menos por ahora). Para referirse a ello - la relación del abogado con el mundo-introduce la idea de "conducta rol diferenciada" como la descripción de la naturaleza de la profesión jurídica. Según Wasserstrom, ser un profesional importa asumir una "conducta rol diferenciada", lo que significa que, mediante una atribución de sentido propia de hechos institucionales, la relación con su cliente provee al abogado de razones que excluyen otras consideraciones que en un contexto a-profesional podrían motivar un curso de acción distinto. Así como la relación de un padre con su hijo importa la operatividad de razones que excluyen (por ejemplo) las reclamaciones equivalentes que pudieran hacer otros infantes de la edad de su hijo cuando se equiparan a las reclamaciones de su propio hijo, y así como un científico no se preocupa por los efectos que pueda tener su estudio sobre la bomba atómica, un abogado debe preferir de un abanico de posibilidades el interés del cliente por sobre el interés de otros individuos en general ${ }^{16}$. Es decir, la profesión jurídica como hecho

14. WASSERSTROM, Richard: "Lawyer as professionals: some moral issues". En: Kaufman, Andrew, Problems in professional responsibility, Third Edition, Little Brown and Company, Law School Casebook series, 1989. Págs. 2-15.

15. Ibíd., Pág. 3. Hay quienes sugieren que el trato del abogado hacia su cliente es el problema fundacional o constitutivo de la ética de la profesión jurídica.

En este sentido la ética de la profesión jurídica se refiere a la moral ajena (la moral del cliente) desde la perspectiva propia (la del abogado). Así SHAFFER, Thomas: "Legal ethics and the good client". En: Catholic University Law Review, 36, 319, Winter, 1987.

16. WASSERSTROM, ob. cit., págs. 5-6. Otro ejemplo interesante es el del sacerdote cumpliendo con el oficio de la confesión. Una comparación algo caricaturesca entre los roles de sacerdote y abogado puede verse en DERSHOWITZ,

Revista de Ciencias Sociales - Número 62 (2013) - Universidad de Valparaíso - ISSN 0716-7725-Valparaíso, Chile 
institucional es para el abogado fuente de razones excluyentes en lo que respecta a su relación con el cliente. Ahora bien, lo que resulta "excluido" en el análisis de Wasserstrom es más que una consideración favorable a intereses equivalentes o contrapuestos a los del cliente. En palabras del autor:

"Una vez que un abogado representa a un cliente, el abogado tiene el deber de poner su experticia completamente a disposición de la realización del fin perseguido por el cliente, sin tener en cuenta el valor moral para el cual se pone en servicio dicho fin o el carácter del cliente que lo persigue" 17 .

En la medida en que el fin perseguido por el cliente no suponga una contravención a normas jurídicas, la asistencia provista por el abogado tendrá una calidad técnica y amoral. Cuando lo dicho se aplica al caso del abogado defensor en un proceso penal, la obligación del abogado de proveer asistencia excluye consideraciones que provengan de su convencimiento sobre la culpabilidad del cliente. El abogado debe proveer una defensa tanto persuasiva como vigorosa a favor del cliente como si se tratase de un sujeto respecto del cual el abogado se encuentra convencido de su inocencia. Ahora bien, la pregunta por la culpabilidad material del imputado no es la única que determina el estándar moral al que está sujeto el abogado en un proceso penal, puesto que también se somete a escrutinio su comportamiento en lo que respecta al uso (o abuso) de mecanismos o prácticas durante el juicio ${ }^{18}$. Si es el caso que el uso de estos mecanismos en estricto provecho del cliente se encuentra justificado, ello se sigue del hecho de que, primero, los clientes necesitan de la asistencia técnica del abogado para llevar adelante ciertas tareas las cuales sin su asistencia no podrían ejecutar, y segundo, lo anterior

Alan, ob. cit., Pág. 41 y ss. Dershowitz entiende que la ética que gobierna la función del sacerdote (quien tiene el deber de mantener el secreto confesional) así como la del abogado, es una de responsabilidad propia del rol (role responsibility) dejando de lado la idea de 'ética situacional' que, según el autor, se ha sugerido en este ámbito.

17. WASSERSTROM, ob. cit., pág. 6.

18. Ibíd., pág. 7.

Facultad de Derecho y Ciencias Sociales - Universidad de Valparaíso - Chile 
exige a los abogados dejar de atender, por irrelevantes, ciertas consideraciones que de otro modo (en otro contexto) serían moralmente relevantes ${ }^{19}$. Hasta aquí se han delineado un par de ideas relevantes que serán exploradas posteriormente en el debate especializado de ética legal. La primera relativa a la relación abogado-cliente caracterizada por el carácter rol-diferenciado de la conducta del abogado (lo que será denominado, con mayor énfasis en el contexto procesal-penal, "defensa celosa" de los intereses del cliente). Y la segunda relativa a la bondad de la perspectiva o rol amoral del abogado cuando se considera su participación en el sistema de persecución penal.

Respecto de la relación entre el abogado y su cliente, Charles Fried, en un muy célebre artículo publicado un año después de la contribución de Wasserstrom ${ }^{20}$, sobre la base de una atención a las mismas críticas a la profesión jurídica que éste considera en su artículo, desarrolla la tesis en virtud de la cual no es sólo jurídicamente sino además moralmente admisible que un abogado adopte como su propósito dominante el favorecimiento de los intereses del cliente ${ }^{21}$. Para apoyar la tesis desarrolla una concepción de la persona ética, y en particular del abogado como un sujeto que intenta constituirse como tal. Sostiene en este orden que una auténtica ética para seres humanos requiere primero reservar un área de autocomplacencia que le permita luego al sujeto moverse con libertad hacia afuera, es decir, hacia un área donde sea posible desarrollar una auténtica preocupación por el bienestar de otros ${ }^{22}$. Cuando le corresponde al abogado preguntarse por su capacidad para someterse a los postulados de la ética, la analogía útil — sostiene Fried - es con la institución de la amistad. Según Fried, el abogado es un amigo del cliente en un sentido limitado o restringido. El abogado es un amigo del cliente restringido al contexto del sistema

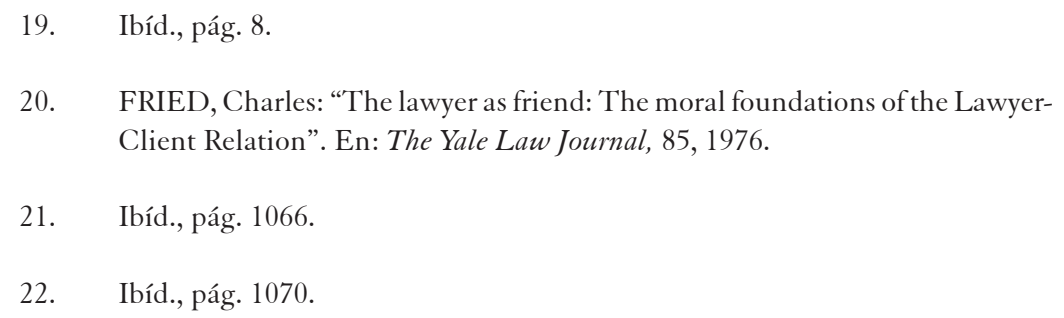


jurídico ${ }^{23}$. Lo interesante aquí de la propuesta de Fried, antes que las aplicaciones a situaciones particulares ${ }^{24}$, es el apoyo que recibe la tesis de una concepción del derecho como hecho institucional complejo, que asigna, en una suerte de red intrincada de roles y fines, un papel al abogado (el de amigo restringido del cliente) de modo de evitar una restricción al acceso que todos los ciudadanos deben tener al sistema judicial, de modo de preservar y fomentar su autonomía ${ }^{25}$. De este modo se revela una matriz muy similar a la de Wasserstrom, lo que muestra la íntima conexión, al menos en la propuesta de Fried, entre la concepción de la función del abogado en relación al cliente y al mismo tiempo respecto de su relación con el mundo.

Un poco más de una década después de la publicación del artículo de Wasserstrom, Stephen Pepper intentaría una defensa explícita del rol amoral del abogado, sobre la base de dicha remisión al valor de la protección de la autonomía de los ciudadanos en una comunidad política ${ }^{26}$. Como todos comienza por la definición de profesión. La idea de profesión, explica Pepper, evoca la función de servicio, "la noción de que en algún sentido el profesional debe subordinar sus intereses a los de aquellos que necesitan de su servicio" ${ }^{27}$. Luego desarrolla las premisas que desde su perspectiva apoyan dicha lógica de subordinación de intereses: la primera premisa dicta que el derecho es un bien público y disponible para todos, y que como tal despliega una variedad de hechos institucionales para la disposición de los ciudadanos en la esfera privada. La segunda premisa nos remite nuevamente al principio de autonomía

23. Ibíd., pág. 1071.

24. Entre ellas, los clientes corporativos, el derecho a la defensa y el problema de los abogados designados. Véase Ibíd., págs. 1075-1080.

25. Ibíd., pág. 1073.

26. PEPPER, Stephen: "The lawyer's amoral ethical role: a defense, a problem, and some possibilities”. En: Kaufman, Andrew, Problems in professional responsibility, Third Edition, Little Brown and Company, Law School Casebook series, 1989.

27. Ibíd., pág. 247.

Facultad de Derecho y Ciencias Sociales - Universidad de Valparaíso - Chile 
individual. Esta premisa "se funda en la creencia de que tanto la libertad como la autonomía son bienes morales, que la elección libre es mejor que la restricción, que cada uno de nosotros espera, en la mayor extensión posible, tomar nuestras propias decisiones antes que otros las tomen por nosotros" ${ }^{\text {28 }}$. Un tercer paso en la argumentación, que combina las dos premisas mencionadas, consiste en vincular la autonomía al derecho, en una relación de dependencia. La autonomía ("ciudadanía de primera clase" como la llama Pepper) es frecuentemente dependiente del acceso al derecho (sistema judicial) ${ }^{29}$. El argumento de la clausura operativa moral de Wasserstrom aquí es extendido y refinado por Pepper cuando sostiene que el acceso material al sistema judicial es posible sólo en la medida en que no esté disponible o justificado una intromisión por parte del abogado a los fines del cliente, o bien un condicionamiento de su participación como tal a la ausencia de vaguedad en la norma ${ }^{30}$. En este sentido no parece aconsejable hacer depender, en último término, el reconocimiento de la autonomía de los ciudadanos del juicio o conciencia individual del abogado.

David Luban respondió el mismo año, con una crítica a la propuesta de $\operatorname{Pepper}^{31}$, que habría de convertirse en una de las (primeras) insignias contra la concepción tradicional de la función del abogado visto como un profesional amoral únicamente interesado en favorecer el interés de su cliente. Para desarrollar su crítica trabaja sobre la segunda premisa del argumento de Pepper (la primacía de la autonomía) negando que el valor de la autonomía sea superior al valor de los actos, analizables desde el punto de vista moral. Es decir, Luban niega que al pretender otorgar un valor importante a la autonomía debamos ser ciegos ante la calidad de los actos que de modo autónomo los ciudadanos

\footnotetext{
28. Ibíd., pág. 249.

29. Ibíd., pág. 250.

30. Ídem.

31. LUBAN, David: "The lysistratian prerogrative: a response to Stephen Pepper". En: Kaufman, Andrew, Problems in professional responsibility, Third Edition, Little Brown and Company, Law School Casebook series, 1989.
}

Revista de Ciencias Sociales - Número 62 (2013) - Universidad de Valparáíso - ISSN 0716-7725-Valparaíso, Chile 
realizan $^{32}$. Para poder vincular dicha afirmación a la pregunta por la moralidad de la profesión jurídica, Luban debe pasar por el alcance y el objeto de la tematización jurídica de conductas. El argumento se desarrolla como sigue: respecto del derecho, es necesario comprender que las razones que apoyan la tematización jurídica de cierto espectro de la conducta social invocan factores que exceden la dimensión de la rectitud moral, e incluyen problemas de vaguedad en la descripción que las normas hacen de la conducta y el costo económico de reforzar las prohibiciones ${ }^{33}$. A partir de esto es fácil concluir que la distinción legal/ilegal se sitúa en un espacio lógico distinto al de la distinción moral/ inmoral. Recordemos que para Pepper considerar la dimensión de la evaluación moral de conductas es relevante porque, en algún sentido, un espacio para dicha evaluación se encuentra al alcance, como ocurre con cualquier sujeto racional, del abogado. El argumento de Pepper apunta al hecho de que resulta ciertamente objetable que el abogado, o cualquier sujeto,

“interponga sus escrúpulos de modo de filtrar los proyectos jurídicamente permisibles de los agentes autónomos. Así, él [Pepper] objeta que se impongan obstáculos informales a la autonomía, permitiendo entonces sólo el despliegue de obstáculos formales impuestos por el derecho" 34 .

Luban declara no preocuparse, a diferencia de Pepper, por la existencia de filtros informales a los proyectos jurídicamente permisibles de los individuos. Invoca la existencia de normas de comportamiento socialmente reforzadas o morales para apoyar la tesis de que, en concreto, "dependemos ampliamente de presiones sociales informales para mantenernos a raya" ${ }^{35}$. Entre estos filtros informales se encuentra la no-cooperación, que aparece entonces como un mecanismo deseable

32. $\quad$ Ibíd., pág. 266.
33. $\quad$ Ibíd., pág. 267.
34. $\quad$ Ibíd., pág. 268.
35. $\quad$ Ibíd., pág. 269.

Facultad de Derecho y Ciencias Sociales - Universidad de Valparaíso - Chile 
de organización social y regulación no institucional del comportamiento. Llevado a la dimensión de la profesión jurídica, la decisión de un abogado de no cooperar con un cliente cuyo fin aquel objeta moralmente, se muestra como una instancia en la que opera un mecanismo informal de coordinación social de acciones, como tal, deseable ${ }^{36}$. Luego, considerando que para Luban la cualidad moral de la acción no es irrelevante, el bien que se obtiene de la decisión de apoyar al cliente que ha decidido llevar adelante un acto significativamente inmoral resulta contrarrestado por el mal que produce la acción inmoral que se propone realizar el cliente. El punto depende de algunas consideraciones de filosofía moral relativas a la relación entre autonomía y libertad que Luban desarrolla para apoyar la idea. Según el autor, para el completo ejercicio de la libertad en ningún caso (ya sea considerado este valor en su dimensión metafísica o psicológica) se requiere promover autonomía de modo ilimitado. Esto en parte porque existen distintas dimensiones en las cuales (considerando los distintos roles que un sujeto puede asumir en la vida social) los individuos pueden ejercer de modo pleno su autonomía. La negativa a cooperar por parte del abogado no vulnera de modo absoluto (como podría pensarse y como parece sugerirlo Pepper) la autonomía de los individuos, en la medida en que sus vidas sean por lo general conducidas de modo autónomo ${ }^{37}$.

Andrew Kaufman también proveyó una crítica al notable artículo de Pepper ${ }^{38}$. Según este autor el problema de la propuesta de Pepper es el mismo que encuentra la de Fried, antes comentada, y dice relación - en principio muy cerca de Luban - con la poca capacidad crítica que le reservan a la evaluación moral, que no tiene espacio para someter a crítica una conducta jurídicamente permitida, y así entonces resulta aceptable que el abogado asista al cliente sin importar el fin

36. Ídem.

37. Ibíd., pág. 270.

38. KAUFMAN, Andrew: "A commentary on Pepper". En, del mismo: Problems in professional responsibility, Third Edition, Little Brown and Company, Law School Casebook series, 1989.

Revista de Ciencias Sociales - Número 62 (2013) - Universidad de Valparáíso - ISSN 0716-7725-Valparáiso, Chile 
(jurídicamente permitido) que éste se proponga. De nuevo, esta perspectiva encierra, supuestamente, una equiparación entre la dimensión de lo jurídico y la de lo moral, pues parece pedir el principio de que la tematización jurídica obedezca a una evaluación moral previa $^{39}$. En contra Kaufman propone imaginar un sistema jurídico que permite a los abogados ejercer libremente su objeción de conciencia al ejercer su profesión. Desde su perspectiva una ética de la profesión jurídica debería

"reconocer que resulta enteramente apropiado para el abogado rechazar el rol amoral en un número significante de situaciones - no solamente en el asunto de selección de clientes, sino también en el desarrollo de las tareas concretas que el cliente espera que el abogado lleve a efecto" ${ }^{40}$.

Según Kaufman es importante notar que los abogados no reconocen en el ejercicio de su profesión de modo nítido - como Pepper y la disciplina académica de la ética profesional en general parecen sugerirlo- aquellas instancias (además de la importante decisión inicial relativa al tipo de profesión que desean ejercer) en las que su desempeño los somete a un estándar evaluativo moral. Parece ser más bien que estas instancias no son particularmente numerosas. Por otro lado, también puede ocurrir que un abogado con un fuerte sentido o conciencia moral decida ante un dilema concreto deferir la decisión moral a su cliente. Esa decisión tiene, afirma Kaufman, un contenido moral. De este modo, el abogado puede no tomar decisiones con contenido moral él mismo pero delegarlas en su cliente. Ello muestra que el ejercicio de su profesión, lejos de ser amoral, en realidad tiene un profundo carácter moral ${ }^{41}$.

Respecto de la crítica de Luban a Pepper, Kaufman decide comentarla a propósito de una propuesta que aparece en el artículo de Pepper, relativa a la autonomía moral (capacidad de actuar como una

\footnotetext{
39. Ibíd., pág. 275.

40. Ibíd., pág. 276.

41. Ibíd., págs. 276-277.
}

Facultad de Derecho y Ciencias Sociales - Universidad de Valparaíso - Chile 
buena persona) de los abogados. La traerá a la escena para declarar que sostiene una posición ecléctica (entre ambos autores) respecto de esta pregunta con alcance amplio. Desde su perspectiva, en las reglas de ética de la profesión jurídica no se aprecia una toma de postura a favor de alguna de las visiones representadas en las propuestas de Luban o Pepper, y esta parece ser la solución ideal: evitar forzar, por medio de una regla, la respuesta a la pregunta por el rol que cumplen los abogados en abstracto, cuando sea el caso que en una situación concreta, éstos se puedan ver forzados a buscar dicha respuesta ${ }^{42}$.

Stephen Pepper responde a las críticas ${ }^{43}$. Comienza recordándonos la intención principal de su artículo: “delinear la relación ética entre abogado y cliente, de modo de proveer una razonada y persuasiva justificación moral para apoyar el tradicional rol amoral del abogado". A partir de la posición ecléctica y algo escéptica de Kaufman (en virtud de la cual parece ser que el mejor camino para delinear el rol moral del abogado es la casuística), Pepper responde defendiendo la necesidad de un modelo filosófico-moral que explique el rol de la profesión jurídica. Ello es necesario — sostiene- porque es raro encontrar abogados con algún conocimiento de filosofía moral, puesto que esta materia por lo general no se enseña en las escuelas de derecho ${ }^{44}$. En segundo lugar, la ausencia de un modelo puede tener como consecuencia el retorno de consideraciones de ética profesional caracterizadas por la primacía del carácter del sujeto, y entonces una disminución preocupante de la importancia de la enseñanza de valores en la educación jurídica de los abogados. Ahora bien, respecto del punto fuerte de Kaufman - la propuesta de dejar la resolución de los problemas que se puedan manifestar a la discreción de los abogados- parece éste situarnos frente a un curioso paradigma, que enfrenta la posibilidad de dejar la resolución de conflictos (y la definición del rol) a los propios profesionales, con la de tener normas de mandato y prohibición que

\footnotetext{
42. Ibíd., pág. 278.

43. PEPPER, Stephen: "A rejoinder to professors Kaufman and Luban". En: American Bar Foundation research journal, N 4, 1986.

44. Ibíd., pág. 658.
}

Revista de Ciencias Sociales - Número 62 (2013) - Universidad de Valparáíso - ISSN 0716-7725-Valparaíso, Chile 
encaucen el correcto desempeño de la profesión. Según Pepper sin embargo, el modelo que provee en el artículo original no pretende en principio ser traducible a reglas específicas. Parece ser más bien que se trata de una meta-reflexión respecto de la naturaleza ética de las obligaciones del abogado y de su rol como profesional en la sociedad ${ }^{45}$.

Respecto de la crítica de Luban, concentrándome en el concepto de autonomía, Pepper parece estar de acuerdo con el autor en la existencia tanto de mecanismos formales como informales de restricción de la autonomía. El derecho es mecanismo formal de restricción y en la comunidad operan mecanismos informales de restricción de la esfera de manifestación de la autonomía individual. Pepper sostiene que la profesión jurídica funciona como parte del sistema formal de restricción de la autonomía y que ese dato permite construir una justificación razonada para construir una ética profesional para la profesión jurídica sobre dicha base. Luban por otro lado, cree que los abogados forman parte de los mecanismos propios de la comunidad, los informales ${ }^{46}$.

Pepper está de acuerdo con Luban en la existencia de mecanismos informales que permitan regular el comportamiento en la esfera privada (estándares que proveen instituciones como la familia y la amistad). El punto entonces es el siguiente: si queremos sostener — como Pepper lo hace- que los abogados forman parte del sistema formal de regulación del comportamiento, entonces es necesario apreciar las diferencias que existen entre éstos y los individuos que juegan roles importantes en instituciones como la familia o la amistad. Es decir, es necesario (en contra de Fried) distinguir al abogado del amigo, o del cónyuge, y distinguir la naturaleza de los deberes recíprocos o unilaterales en cada caso $^{47}$. Nuevamente la pregunta por la naturaleza del derecho como hecho institucional viene a lugar, pues Pepper enfatiza la concepción del derecho como sistema formal, y como tal el acceso a éste (lo que llamamos coloquialmente "acceso a la justicia") por medio del abogado como un elemento crucial en el análisis del vínculo entre la ética de la

\footnotetext{
45. Ibíd., pág. 659.

46. Ibíd., Pág. 664.

47. Ibíd., pág. 665.
}

Facultad de Derecho y Ciencias Sociales - Universidad de Valparaíso - Chile 
profesión jurídica y el valor de la autonomía. Lo contrario —entender a los abogados como formando parte del sistema informal- supone entender al derecho como un sistema contingente, en el sentido de las normas de comportamiento sociales. Ello supone —en palabras de Pepper - una "informalización y subjetivización del derecho" ${ }^{48}$. Lo apropiado es entender que.

" $[\mathrm{t}$ ] anto la autonomía como la igualdad son honradas en nuestra sociedad gracias a los abogados que actúan sobre la base de una ética de roles que crea un tipo (y quizás un grado) de obligaciones formales muy distintas de aquellas que se aprecian en los roles éticos informales del cónyuge o del amigo"49.

\section{La institucionalización de las reglas de ética profesional}

Qué forma debiera adoptar la ética de la profesión jurídica? Una opción evidente son los códigos disciplinarios. No quisiera referirme aquí a la cuestión teórica relativa a la concreción normativa de la dimensión práctica de la ética en general, sino más bien concentrarme en la institucionalización de la ética de la profesión jurídica, para acercarnos de mejor manera a la reforma chilena.

Respecto de la formalización de las normas éticas mediante la codificación, ello tiene la ventaja de proveer sanciones concretas que permiten reforzar las normas de conducta que se describen en los códigos. El problema es obvio, parece reducir la ética a una mera forma de regulación jurídica ${ }^{50}$, que sin embargo no satisface el principio democrático de producción de normas jurídicas, pues se trataría de reglas de mandato y prohibición dadas por la propia profesión, siguiendo la lógica de la autorregulación de la profesión moderna. El problema

\footnotetext{
48. Ibíd., pág. 666.

49. Ídem.

50. SAMPFORD, Charles y PARKER, Christine: "Legal regulation, ethical standard-setting, and institutional design”. En: Parker, Sampford, (eds.) Legal ethics and legal practice: contemporary issues, Clarendon Press, Oxford, 1995, pág. 15.
}

Revista de Ciencias Sociales - Número 62 (2013) - Universidad de Valparáíso - ISSN 0716-7725-Valparaíso, Chile 
fundamental, sin embargo, radica en que las reglas codificadas sólo expresan el denominador común básico en términos del comportamiento éticamente desaprobado en el universo de la ética de la profesión jurídica $^{51}$. La pregunta por el reforzamiento entonces surge como la más relevante: ¿En qué sentido las normas codificadas "refuerzan" un set de valores morales preestablecidos? ¿No puede ser más bien el caso que las reglas de mandato y prohibición requieren el desarrollo posterior de una moral positiva que las dote de sentido? Aquí es donde la tarea codificadora de los entes reguladores establecidos para dicho fin y su trabajo de producción de normas codificadas debe analizarse bajo una determinada luz, pues.

"una eventual normación interna profesional puede ser, o bien reconocedora de una realidad normativa que ya existe, o bien creadora de normas de comportamiento que son requeridas por las nuevas exigencias de la vida profesional y moderna" ${ }^{2}$.

De cualquier modo, lo que resulta necesario elucidar para avanzar es la naturaleza de las normas de ética profesional en abstracto. En concreto, como veremos, la cuestión depende de los mecanismos institucionales dispuestos en cada caso para reforzar las normas. Desde ya ocupar algún catálogo elaborado en sede de teoría de las normas puede resultar muy provechoso. No nos dedicamos a ello aquí.

Respecto de su asimilación a normas jurídicas, y en particular a normas punitivas, en abstracto, se insiste cada vez más en el camino opuesto, en la diferenciación. Ello por medio de un énfasis en la vinculación directa entre las reglas disciplinarias ${ }^{53} \mathrm{y}$ los principios

51. Ídem.

52. LEGA, Carlo: Deontología de la profesión de abogado. (Traducción de Miguel Sánchez Morón), Madrid, Civitas, 1983, págs. 57-58.

53. En la literatura especializada comúnmente se provee una distinción a veces poco nítida entre pautas de conducta (normas que describen un supuesto de hecho contrafáctico) y el régimen disciplinario (que lo dota de rasgos punitivos) que se supone satisface una suerte de principio de certeza pues permite al profesional conocer no sólo la conducta prohibida sino también las sanciones. Del mismo modo

Facultad de Derecho y Ciencias Sociales - Universidad de Valparaíso - Chile 
(programáticos) éticos sobre los que se fundan los códigos profesionales. El problema, claro está, radica en que gran parte de la literatura suele apuntar, en primer lugar, al valor de la justicia como principio informador del proyector codificador ${ }^{54}$. Ello puede plantear una aparente superposición problemática de principios en las dimensiones del derecho y de la moral. El problema es aparente, pues, en algún sentido, resulta útil para insistir en la diferenciación de ambas dimensiones de regulación del comportamiento, puesto que, desde la perspectiva de la teoría del derecho formalista contemporánea, este hecho institucional funciona como un sistema regulativo que permite resolver desacuerdos de manera exclusionaria, es decir, excluyendo precisamente los argumentos que se desempeñan mejor en la dimensión abstracta del desacuerdo (y que, por tanto, no se desempeñan bien en sede de aplicación judicial) en torno a la mejor concepción del principio de justicia.

Ahora bien, es cierto que la flexibilidad que la — aparentemente nítida distinción comentada, elaborada sobre la base de la relación de transitividad entre los principios y las reglas y su contexto de aplicación, da lugar a casos problemáticos, entre los cuales ciertamente se encuentran los códigos de ética, no sólo compuestos por normas que enuncian principios programáticos sino también — como se mencionó por normas cuyos enunciados describen y tipifican un comportamiento, y entonces someten el supuesto de hecho al proceso de subsunción en el contexto de justificación. Es decir, por normas con un operador deóntico evidente.

Si nos tomamos en serio el llamado a una reflexión extensiva que hace Williams y gran parte de la literatura sobre ética profesional, podremos llegar a plantear cuestiones diferentes, lejos de la pregunta por la propiedad cualitativa de las normas de los códigos de ética, y

es una garantía para el cliente, en la medida en que la amenaza de sanción incrementa la confianza en el sentido que asegura las expectativas de comportamiento (disminuye la contingencia). VÁZQUEZ, Francisco: Ética, deontología y abogados, Barcelona, Eiunsa S.A., 1996, pág. 39.

54. Así, en la literatura española, VÁZQUEZ, Ibíd., págs. 43 y ss. También, de modo más sofisticado, SAMPFORD y PARKER, ob. cit., págs. 21 y ss.

Revista de Ciencias Sociales - Número 62 (2013) - Universidad de Valparáíso - ISSN 0716-7725-Valparáiso, Chile 
cercanas más bien a las reflexiones orientadas a resolver el desacuerdo moral. Así, por ejemplo, la distinción entre moral positiva y moral crítica tiene utilidad para insistir en la importancia de profundizar el debate en dicha dimensión. Sobre dicha base, se ha propuesto hacer rendir una forma de idealismo (individualista) moral, que permita someter valores anclados en normas codificadas al escrutinio de la así llamada moral crítica. Asumiendo esta perspectiva, su mecanismo óptimo de institucionalización parece ser el trabajo en grupos de abogados dedicados a discutir problemas y soluciones de meta-ética (valores) y ética práctica (problemas concretos). Charles Sampford los denomina "círculos de ética" (ethical circles) ${ }^{55}$, y los describe como grupos de trabajo en los que los abogados individuales expresan puntos de vista, discuten problemas éticos prácticos y de ese modo desarrollan paulatinamente una moral crítica, lo que a su vez permite avanzar hacia una moral positiva sólida y compartida ${ }^{56}$. Se pretende que estos grupos se constituyan como espacios o foros de discusión que "tiendan hacia la convergencia de opiniones y la clarificación de diferencias" ${ }^{57}$. Lo que se espera en último término como resultado de esta lógica de trabajo es una asistencia, por medio del ejercicio de moral crítica, a la mejora de la moral positiva existente, lo que se expresa finalmente en el desarrollo de propuestas refinadas y sofisticadas de normas de ética profesional $\operatorname{codificadas}^{58}$. De modo tal que incluso una propuesta singular como la de estos autores termina sugiriendo como la mejor expresión institucional de los valores y principios programáticos de la profesión jurídica un cuerpo de normas codificadas y respaldadas por reglamentos y sanciones.

Ahora bien, el mecanismo particular de reforzamiento de las normas, es decir, el organismo encargado de ejecutar las sanciones y la cualidad de éstas, es relativo al ordenamiento jurídico, y determina en

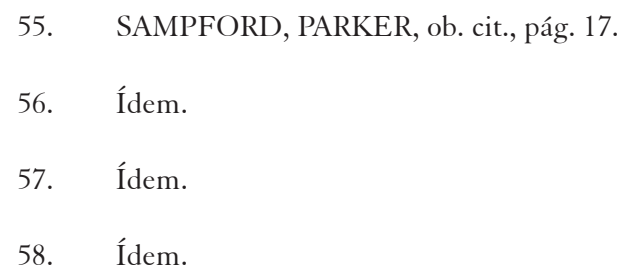


gran parte el rango posible de comparación entre normas éticas y otros tipos de normas, en particular normas jurídico-penales.

Quisiera concluir la presente sección con una reflexión, en la dimensión abstracta, sobre la incidencia de estas diferencias cualitativas en nuestra concepción de la ética de la profesión jurídica, entendida como una forma de ética práctica y como un conjunto de reglas institucionalizadas que promueven determinados valores en torno a la profesión jurídica, y que como tales promueven una concepción determinada del derecho.

Thomas Giegerich, en un trabajo publicado a fines de los 70,59, condensa y comenta gran parte de la discusión que hemos desarrollado en el presente capítulo introductorio, insistiendo siempre en el carácter (podríamos decir) no-trivial de la(s) pregunta(s) fundamental(es) de la ética de la profesión jurídica, ¿’es esto "ética”? Preocupación que abre otras interrogantes, a saber: ¿Estamos haciendo referencia a estándares jurídicos o propiamente éticos? ¿Qué valores promueven estos estándares? Y lo más importante ¿de qué modo la institucionalización de normas de ética profesional — vía códigos de ética- resuelve los cuestionamientos planteados?

Tratemos en abstracto simplemente con la idea de un código de ética profesional, sin hacer referencia a un cuerpo de normas específico (ciertamente no al chileno). Giegerich sugiere que podemos considerar un cuerpo de normas de dicha calidad como un instrumento que configura o establece estándares (de comportamiento) propiamente jurídicos, reservando de todos modos para la conciencia (subjetiva) del destinatario de los mandatos o prohibiciones que en dicho instrumento se puedan encontrar (los abogados) el juicio último respecto de la rectitud (lo bueno y lo malo) del comportamiento propio de la práctica y la operatividad de algún estándar propiamente moral (o ético) a su conciencia moral, a la cual el sujeto tiene ciertamente un acceso privilegiado $^{60}$. Luego, en definitiva, un código de ética no parece

59. GIEGERICH, Thomas: "The Lawyer's Moral Paradox". En: Duke Law Journal 1335-1358, 1979.

60. Ibíd., pág. 1336.

Revista de Ciencias Sociales - Número 62 (2013) - Universidad de Valparáíso - ISSN 0716-7725-Valparáiso, Chile 
funcionar u operar como una guía moral, o como un set de directrices para evaluar moralmente posibles cursos de acción. Esto porque no reclama una validez moral de modo más especial o particular en comparación a cualquier otro sistema de resolución de problemas de coordinación ${ }^{61}$. Aquí (y en esto las normas generales que son objeto de análisis por el autor — el Model Code americano- y el CEP chileno encuentran puntos de acercamiento interesantes) se apoya el autor en la similitud que muestran en términos de estructura y de despliegue de prescripciones, las normas de los códigos de ética con las normas jurídicas. Entre ellas la más relevante similitud $-\mathrm{y}$ que se ha omitido en este trabajo - se aprecia en la posibilidad de revisión y modificación por individuos investidos con la autoridad para ello, por medio de los mecanismos institucionales dispuestos para ese objeto; posibilidad que descarta o excluye (aquí el autor extrae la conclusión de una observación de H.L.A. Hart en una nota al pie) su caracterización como normas propiamente morales ${ }^{62}$. Adicionalmente señala el autor, ya no como punto de acercamiento entre las reglas de los códigos y las normas jurídicas sino como elemento diferenciador respecto de aquellas y las normas morales, el hecho de que las reglas de los códigos tienen como objetivo (además de la resolución de eventuales problemas de coordinación) la promoción del bien de la comunidad como un todo, antes que el desarrollo moral del individuo ${ }^{63}$.

En la sección siguiente del trabajo, Giegerich enfrenta el dilema que plantea este tipo de normas de modo directo. Me refiero a la cuestión de la separación entre derecho y moral. Asume como punto de partida la tesis en virtud de la cual el objeto del derecho y el de la moral se relacionan en torno a la promoción del valor de la justicia. Asumiendo que un código de ética de abogados opera como (tiene el mismo rendimiento que) un set de normas jurídicas, entonces podemos afirmar que promueve ciertos valores morales, y entonces se relaciona con la

\footnotetext{
61. Ibíd., pág. 1337.

62. Ibíd., pág. 1338.

63. Ídem.
} 
moral. Luego eso lo dota de, lo que el autor llama, un valor normativo informacional. Las premisas operativas que sostienen lo anterior son tres. Primero, que los abogados, como todas las personas, buscan con sus acciones promover el bien de la comunidad. Segundo, que el código de ética tiene, en tanto derecho, el propósito de promover el bien de la comunidad y en específico (también) el propósito de promover la administración justa de las leyes de una sociedad. Tercero, la función última del abogado es administrar y facilitar el funcionamiento del derecho. Consideradas las tres premisas se concluye que el código de ética posee un valor normativo-informacional positivo, esto es, informa a los abogados en lo que respecta a sus cursos de acción tematizables moralmente, aunque no constituye los valores morales propios de la profesión ${ }^{64}$. En rigor, con la instauración de normas en un código de ética de abogados se espera beneficiar al público en general ${ }^{65}$.

Ahora sometamos lo anterior a un test de plausibilidad. El autor del trabajo que estamos considerando reproduce más adelante parte del debate entre (el célebre autor y abogado norteamericano) Monroe Freedman y Marvin Fraenkel para concluir que en la formulación de reglas de ética profesional (por ejemplo, en un código de ética profesional) se desarrolla un contraste o un choque entre valores morales propios de la profesión que muestran (de este modo) que la determinación de los principios que deben guiar el ejercicio de una profesión es una tarea difícil y delicada ${ }^{66}$. El debate entre Fraenkel y Freedman gira en torno a la idea de un proceso adversarial, donde se espera que el abogado defienda los intereses de su cliente de modo leal y partidista. Mientras Fraenkel sostiene que con la instauración de reglas (de ética profesional) que consagren el valor de la lealtad abogadocliente (o que impongan de alguna forma el mandato al abogado de comportarse de modo leal a los intereses de su cliente) de algún modo se sacrifica el valor de la justicia que se espera informe el diseño del

\footnotetext{
64. Ibíd., pág. 1340.

65. Ibíd., pág. 1341.

66. Ibíd., pág. 1344.
}

Revista de Ciencias Sociales - Número 62 (2013) - Universidad de Valparáíso - ISSN 0716-7725-Valparaíso, Chile 
proceso judicial, Freedman apunta a la importancia (para la profesión jurídica) del principio de confidencialidad entre abogado y cliente, que hace posible el acceso a la justicia de los ciudadanos en la medida en que sienta las bases para una relación de confianza entre abogado y cliente $^{67}$. Giegerich trata este (célebre) intercambio como un ejemplo paradigmático que ilustra la dificultad del proceso de diseñar las reglas propias de la profesión jurídica, que se espera se encuentren sostenidas o informadas por principios de naturaleza jurídica. Esto permite concluir que con la instauración de una regla particular de ética profesional no se puede pretender reforzar un particular principio ético. Más bien, es necesario tratar la actividad legislativa de los códigos de ética profesional como el ejercicio de una política (policy) legislativa; como una suerte de compromiso, como el establecimiento de un diseño o de un proyecto que no asume una cierta forma de significancia normativa última, sino que espera mostrar en su ejecución (de las reglas) la existencia de diversos valores contrapuestos, que compiten en un escenario de conflicto a la espera de la (re)solución más razonable ${ }^{68}$.

Existe una pretensión — según el autor - que se satisface por medio de la instauración de un set de reglas como las del código de ética de la profesión jurídica, de identificar aspectos y alcances de un criterio de rectitud propio de la profesión jurídica. No se pretende, por tanto, regular el comportamiento de los abogados identificando claramente valores y principios morales que se espera les sirvan como razón para la acción en casos concretos, sino más bien identificando los alcances del criterio de rectitud propio de la profesión, es decir, haciendo referencia al bien que se obtiene estableciendo los límites del ejercicio de la profesión de abogado $^{69}$. Dado que las reglas cumplen una función informativa (respecto de estándares éticos), ello tiene consecuencias para el caso de una regla deficiente o poco clara (esto es, que no sirve como directriz para la acción en un caso particular) pues en este caso, el abogado (quien es el destinatario de la norma de comportamiento) debe acudir a su
67. Ídem.
68. Ídem.
69. Ibíd., pág. 1345.

Facultad de Derecho y Ciencias Sociales - Universidad de Valparaíso - Chile 
convicción subjetiva (respecto de la moral) para proveerse de una razón o directriz para la acción ${ }^{70}$, así como en el caso de una norma propiamente jurídica el juez debe acudir a principios (morales y políticos) ante una regla deficiente o poco clara. Esto básicamente significa que todo aquello que el CEP no regula o no resuelve queda sujeto al ejercicio de la conciencia moral individual del abogado.

En lo que respecta a este carácter bi-dimensional de la ética profesional, un ejemplo interesante, aunque no esté relacionado con el problema de las reglas defectuosas, es el de la representación del cliente inmoral; esto es, el caso, profusamente discutido en la literatura especializada, del cliente respecto del cual el abogado manifiesta una convicción en lo que dice relación con los hechos respecto de los cuales se predica su participación y culpabilidad. Sobre la base de este conocimiento, se discute la posibilidad de entregar un espacio al abogado para que haga uso de su criterio moral personal y entonces desista de representar al cliente que cree es culpable. Giegerich desarrolla este problema en su artículo a propósito de la bi-dimensionalidad de la ética de la profesión jurídica. El hecho de que cierta norma del Code of Ethics permita al abogado desistir de representar a un cliente (anteponiendo su convicción moral personal) resulta una prueba suficiente de que para el código de ética profesional el abogado es una persona, y como tal es capaz de sostener convicciones morales, y todavía más, le permite ejercerlas en casos particulares ${ }^{71}$, aún cuando desde cierta perspectiva el abogado sea parte importante de la administración del derecho, en tanto permite a los ciudadanos acceder al foro donde sus demandas jurídicas pueden resultar satisfechas. En nuestra regulación doméstica el art. 14 del CEP entrega al abogado,

"la libertad para aceptar o rechazar los encargos profesionales sin necesidad de expresar los motivos de su decisión”.

Lo anterior sugiere, primero, que la convicción moral subjetiva del abogado puede permanecer en su fuero interno y constituir una

\footnotetext{
70. Ibíd., págs. 1347-1348.

71. Ibíd., págs. 1349-50.
}

Revista de Ciencias Sociales - Número 62 (2013) - Universidad de Valparáíso - ISSN 0716-7725-Valparáiso, Chile 
razón que motiva el rechazo de asistencia de determinado cliente, y segundo, que lo anterior solo es posible en la medida en que la designación no esté mediada por cierto mecanismo institucional. En el código de 1948 se hacían explícitas las razones que permitían renunciar al patrocinio de un cliente. El artículo $30^{\circ}$ de dicho código señalaba:

“[u]na vez aceptado el patrocinio de un asunto, el abogado no podrá renunciarlo sino por causa justificada sobreviniente que afecte su honor, su dignidad o su conciencia (...)”.

Se entregaba, entonces, un espacio claro a la conciencia personal del abogado como fundamento posible para una objeción que constituyera un desistimiento o renuncia a la representación de determinado cliente.

La conclusión del artículo en comento es la que adelanta su título: el abogado enfrenta en el ejercicio de su profesión una 'paradoja moral' (moral paradox). Debe enfrentar dos mandatos que parecen, al formularse, contrapuestos: hacer lo que es debido y vivir como es debido. Hacer lo que es debido significa intentar remover el estigma del abogado como un profesional que actúa en un universo absolutamente a-moral. Supone adscribir a ciertos valores como la honra de la profesión jurídica, en tanto se asume que el abogado es una pieza esencial del derecho como sistema institucional pues permite a los ciudadanos acceder al foro en el que reclaman justicia ${ }^{72}$. Vivir como es debido para un abogado es complejo, ya que se trata de una profesión paradigmáticamente conflictiva. Se trata de una profesión en la que parece exigirse al sujeto que entre en conflicto con todos, con sus compañeros en el contexto de un juicio, con sujetos ajenos al juicio, y con su cliente si el caso que manifiestan intereses inconciliables. Aquí ya no hay —afirma el autor nada que agregar en términos académicos, pues la cuestión queda para ser resuelta por la sociedad y en relación a la opinión que sostenga respecto de los profesionales que ejercen la función de abogado ${ }^{73}$.

72. GIEGERICH, ob. cit., págs. 1354-55.

73. Ibíd., págs. 1355-57.

Facultad de Derecho y Ciencias Sociales - Universidad de Valparaíso - Chile 


\section{Las dos concepciones de la función del abogado}

En The Practice of Justice ${ }^{74}$, William Simon sostiene que la ética de la profesión jurídica ha sido dominada por una concepción — que de hecho denomina 'concepción dominante'- cuya idea nuclear es que el abogado tiene el deber, o al menos la posibilidad, de perseguir cualquier fin que se proponga el cliente por medio de cualquier curso de acción aunque sea jurídicamente cuestionable ${ }^{75}$. Esta concepción dominante tiene su base en las dos normas principales de la regulación de ética profesional norteamericana, que de modo más o menos explícito consagran el estándar del partidismo celoso brevemente comentado en el capítulo anterior ${ }^{76}$. En la introducción al libro, Simon comenta su propuesta de una concepción alternativa a la dominante, la cual denomina 'concepción contextual'.

Luego del capítulo introductorio, Simon comienza a exponer las bases y fundamentos de la así llamada concepción dominante, con la sugerencia ciertamente tendenciosa de que, en definitiva, el argumento clásico a favor de la concepción dominante sostiene que el cliente tiene derecho a una forma de abogacía con un estándar de desempeño determinado, que en su satisfacción no depende de la consideración de las pretensiones de terceros, por lo que, podríamos decir, éstos tienen un "derecho a la injusticia". Es decir, la abogacía agresiva que la concepción dominante prescribe se ejerce a pesar de la injusticia que sufren, o puedan sufrir, terceros ${ }^{77}$.

La cuestión interesante, y que se muestra en el tratamiento que hace Simon de la lógica de la concepción dominante, es que el proyecto se sostiene sobre bases particularmente sólidas, esto es, sobre dogmas o principios teóricos que pueden al mismo tiempo servir de justificación para cierta concepción del sistema jurídico en general, con lo que se

\footnotetext{
74. SIMON, William: The Practice of Justice, Harvard University Press, 2000.

75. Ibíd., pág. 7.

76. Ibíd., pág. 8.

77. Ibíd., pág. 26.
}

Revista de Ciencias Sociales - Número 62 (2013) - Universidad de Valparáíso - ISSN 0716-7725-Valparaíso, Chile 
muestra con particular nitidez la cercanía entre ambas cuestiones. Me refiero a los fundamentos en los principios del libertarianismo y del positivismo ${ }^{78}$. El primero postula la importancia del derecho (y del acceso al sistema judicial) como un mecanismo de aseguramiento de la autonomía de los ciudadanos ${ }^{79}$. El segundo una concepción del derecho siguiendo una tradición que se remonta a Austin y pasa por Hart y Raz. Ambas ideas se sintetizan - explica Simon - en la máxima que llama a los abogados a desempeñarse como partidistas celosos dentro de los márgenes de lo jurídicamente permitido ${ }^{80}$.

Ahora bien, el aporte del positivismo como premisa fundamental de la concepción dominante y del estándar de partidismo celoso se reconoce de un modo particular en las Reglas Modelo estadounidenses, donde parece ser que se asume una postura menos libertaria y más bien instrumental de la función del representante judicial, donde se reconoce su aporte como una institución fundamental en la búsqueda del objeto del proceso judicial y del derecho, la justicia a largo plazo ${ }^{81}$. Llevado a la lógica del modelo adversarial, la concepción dominante eleva críticas contra las normas o propuestas que supongan una ampliación de la responsabilidad del representante judicial y que alcance los actos que afecten a individuos distintos del cliente ${ }^{82}$. Se alega que dichas normas son inconsistentes con el modelo adversarial ${ }^{83}$. En respuesta Simon

\footnotetext{
78. Ibíd., págs. 27 y ss.

79. Este punto es similar al argumento relativo a la ciudadanía de primera clase de Wasserstrom y Pepper revisado más arriba.

80. SIMON, ob. cit., pág. 28.

81. Ibíd., pág. 53.

82. Un ejemplo podría ser el deber de apoyar la magistratura del art. 93 CEP y el de actuar con veracidad ante los medios de comunicación del art. 101 CEP. También el de respetar acuerdos con otros abogados del art. 109 y las reglas sobre asunción de responsabilidad por actuación de terceros del Título II de la sección Cuarta del CEP.

83. SIMON, ob. cit., pág. 62.

Facultad de Derecho y Ciencias Sociales - Universidad de Valparaíso - Chile
} 
argumenta que el sistema procesal penal adversarial (al menos el estadounidense) siempre ha reconocido una dualidad de roles por parte del abogado, tanto como partidista celoso de los intereses del cliente como "oficial de la Corte", es decir, como servidor de la justicia ${ }^{84}$. Esta afirmación nos interesa explorar pues puede decirse que ocurre un fenómeno similar en la ética profesional chilena, donde se materializan dos principios en el título preliminar del CEP, representando cada uno un rol particular. Así, el art. $4^{\circ}$ consagra el deber de defensa empeñosa del cliente, lo que puede entenderse como una expresión de la concepción dominante que sigue el estándar de partidismo celoso y abogacía agresiva en persecución de los intereses del cliente. Por otro lado (antes) el art. $2^{\circ}$, que lleva como título "Cuidado de las instituciones", dispone que,

"Las actuaciones del abogado deben promover (...) la correcta y eficaz administración de justicia, y la vigencia del estado de derecho".

Las normas generales del CEP de 1948 contenían en el art. $1^{\circ}$ una mención (como principio programático) a la calidad de servidor de la justicia y colaborador de la administración del abogado. Luego de ello consagraba el deber de defensa empeñosa de los derechos de su cliente "con estricto apego a las normas jurídicas y morales", referencia que ahora hace el art. $4^{\circ}$ al final (agregando además de las normas jurídicas y morales, la observancia de estándares de buen desempeño profesional). De este modo, el CEP de 1948 consagraba en una única norma (su primer artículo) el carácter dual del rol del abogado, como servidor de la justicia por una parte, y como defensor empeñoso de los intereses de su cliente, por otra.

Una posibilidad de tratar la tensión fundamental entre ambos roles $^{85}$ es mediante una precisión del alcance de la idea del abogado

84. Ibíd., pág. 63.

85. La tensión ha recibido importante atención en la literatura de ética profesional angloamericana, entre otros, véase DEERING, Christopher: "Candor towards the tribunal. Should an attorney sacrifice truth and integrity for the sake of the client?". En: Suffolk U. Law Review, 31, 59, 1997-1998, discutiendo los dos roles del abogado a propósito del deber de honradez hacia el tribunal. Sobre la base de jurisprudencia,

Revista de Ciencias Sociales - Número 62 (2013) - Universidad de Valparáíso - ISSN 0716-7725-Valparáiso, Chile 
como "servidor de la justicia". La cuestión es compleja, en la medida en que de alguna forma la nueva regulación de ética profesional pretende evitar ciertos estereotipos anquilosados referidos a la concepción del abogado. Así, una concepción del abogado como un sujeto cuya formación profesional lo hace inherentemente virtuoso hacía comprensibles, durante la segunda mitad del s. XX, descripciones de los deberes derivados de dicha concepción alcanzando, por ejemplo, el mandato de convertirse en "propulsor entusiasta de la modificación o supresión [de una ley injusta]" ${ }^{86}$. Actualmente, la tendencia al normativismo (ético y jurídico) reemplaza la invocación de un carácter virtuoso como la métrica o el criterio de reconocimiento de las conductas indeseables desde el punto de vista profesional. Por esa razón tanto el deber de lealtad con el cliente $\left(\operatorname{art} .3^{\circ}\right.$ ) como el de defensa empeñosa de sus intereses $\left(\right.$ art. $4^{\circ}$ ) reconocen como límites únicamente las normas éticas del propio código que los consagra, y las normas jurídicas. Por lo anterior, el desarrollo de la tensión transversal a las distintas funciones del abogado - y en particular del abogado defensor en el proceso penal - requiere de un tratamiento más sofisticado.

"La objeción básica a la concepción dominante es que ésta atenúa excesivamente la responsabilidad del abogado por su conducta y requiere de éste que participe en una injusticia" ${ }^{87}$. Con estas palabras Simon comienza a preparar el camino para la exposición de los elementos fundamentales de la concepción alternativa de la profesión jurídica, y al desarrollo, entonces, de la tensión fundamental. Su propuesta, sin embargo, y a diferencia de otras críticas más bien tradicionales a la

sostendrá que en caso de conflicto entre ambos roles, aquel que proyecta un deber para con la judicatura (rol como servidor de la justicia) debe primar (Pág. 66). También Luban sugerirá que la tensión fundamental existe entre una concepción del abogado como activista republicano de reformas jurídicas y políticas contra una concepción que lo concibe como un partisano neutral. Así, LUBAN, David: "The disengagement of the legal profession: Keller v. State Bar of California”. En: The Supreme Court Review, 1990, págs. 189-191.

86. SILVA BASCUÑÁN, Alejandro: El abogado, un servidor de la justicia, Editorial Jurídica de Chile, Santiago, Chile, 2010, pág. 85.

87. SIMON, ob.cit., pág. 109.

Facultad de Derecho y Ciencias Sociales - Universidad de Valparaíso - Chile 
concepción dominante, mira mucho más de cerca la función del abogado y la modelación por la que pasa al situarse en el contexto propio de su desempeño como profesional, antes que su tendencia a la injusticia como un elemento exógeno o externo. Así, como punto de partida sugiere Simon que, bajo la concepción dominante se esconde una poco atendida alienación personalmente costosa para el profesional, en relación con el contexto en el que se desempeña ${ }^{88}$, lo que conlleva una suerte de pérdida de la dimensión moral de la agencia por parte del sujeto, dada la pérdida de autonomía que la sujeción a las reglas propias del ejercicio profesional supone; y sin embargo, en el caso de los abogados, el manejo de reglas y estrategias de aplicación constituye el aspecto decisivo en relación al buen desempeño profesional, al mismo tiempo que resulta característico de esta función la tendencia a desconocer la responsabilidad por las consecuencias de sus acciones ${ }^{89}$. En respuesta a la crítica de la alienación es posible levantar las diferencias entre el ejercicio de una profesión y el ejercicio de trabajo dependiente. En este ámbito la particularidad de la profesión jurídica es resaltada por autores como Wendell Holmes quien destacaba el aspecto contemplativo y reflexivo propio de la profesión jurídica, tanto en la educación jurídica como en el ejercicio de la profesión, al hacer un llamado a quienes ejercieran la profesión jurídica a disfrutar en soledad la dicha del pensador o intelectual ${ }^{90}$. Otros sugirieron como respuesta que la institución de la profesión en sí misma era capaz de producir ese tipo de trabajo que podía ser experimentado al mismo tiempo como auto-expresión (como desarrollo personal) y como sujeción a normas sociales, y de este modo escapaba al problema de la alienación ${ }^{91}$. De este modo la idea de la profesionalización se transforma en una respuesta a una serie de preguntas, entre ellas la del trabajo significativo y de la organización y división del trabajo productivo ${ }^{92}$. Aquí entra a jugar su
88. Ibíd., pág. 110.
89. Ibíd., pág. 114.
90. Ibíd., pág. 121.
91. Ídem.
92. Ibíd., pág. 124.

Revista de Ciencias Sociales - Número 62 (2013) - Universidad de Valparáíso - ISSN 0716-7725-Valparaíso, Chile 
rol lo que Simon presenta como 'proyecto progresivo-funcionalista', que se caracteriza, primero, por insistir en el desarrollo de un modelo institucional de auto-gobierno y control de la admisibilidad a la institución profesional, y segundo, por sostener una concepción de la dimensión de lo jurídico que mostrara al oficio como una instancia en la que era posible la convergencia tanto de lo abstracto como de lo particular. Este proyecto en último término dará origen a una concepción contextual de la profesión jurídica y del trabajo jurídico en general, en cualquiera de sus dimensiones. Esta concepción entiende que las normas que regulan y dotan de sentido a las instituciones jurídicas funcionan como estándares generales pero que dependen para su aplicación y correcta inteligencia, de una atención a las circunstancias particulares. En este sentido es una concepción realista. En lo que respecta a la concepción de la jurisdicción, suele vincularse - explica Simon - a la idea de 'activismo judicial' en sociedades democráticas, pero la preocupación central siempre es, por parte de los autores relevantes, la mejor representación de la idea de trabajo significativo o expresivo ${ }^{93}$.

La concepción contextual, como alternativa a la concepción dominante de la abogacía como agresiva y partisana, se encuentra a estas alturas de la obra en condiciones de ser presentada de modo suficientemente detallado. Nuevamente la justicia como valor del derecho y del proceso judicial aparece jugando un rol central. Según Simon, la concepción contextual justifica o reclama por parte de los abogados el uso de los recursos disponibles para llevar adelante las medidas que, considerando las circunstancias relevantes del caso particular, tiendan a la promoción de la justicia, entendida no como un valor de moral tradicional o propio de preferencias personales, sino como un argumento jurídico que surge de la autoridad propia de la cultura profesional $^{94}$. La búsqueda de justicia, como objetivo o principio programático en algún sentido extractable o derivable de los términos

93. Ibíd., pág. 126.

94. Ibíd., pág. 138. En este sentido, explica, se trata de un uso del concepto 'justicia' que es intercambiable con el de 'mérito jurídico'.

Facultad de Derecho y Ciencias Sociales - Universidad de Valparaíso - Chile 
del art. $2^{\circ} \mathrm{CEP}$, no aparece en contradicción en abstracto con pronunciamientos generales o dictámenes autoritativos como los que provienen del legislador o de los jueces, ni tampoco con la promoción del funcionamiento eficaz de la administración de justicia, mas Simon alega en contra de algunas intuiciones básicas que resulta concordante con el ideal de abogacía agresiva y partidismo celoso ${ }^{95}$. De modo preliminar es posible afirmar que el proyecto descansa sobre una concepción del derecho profundamente contraria al positivismo contemporáneo. Ello se muestra de modo claro a partir de los contrastes que ofrece el mismo Simon, que él presenta como las tensiones propias de la ética de la profesión jurídica: sustancia contra procedimiento, propósito contra forma, y amplia contra estrecha contextualización. Luego de la exposición de cada una, se supone que su presentación de la concepción contextual favorecerá los elementos de estos binomios que encajen con su respuesta a la pregunta por el rol del abogado, en virtud de la cual se sostiene que éste está llamado a resolver los dilemas éticos que se presenten tomando una decisión como si fuera un juez, en particular, como si fuera un juez actuando como activista ${ }^{96}$.

Habiendo presentado el contraste entre ambas concepciones de modo general, corresponde al autor enfrentar la predominancia indiscutida de la concepción del partidismo celoso referida la institución de la defensa penal. En el penúltimo capítulo del libro, titulado "Is criminal defense different?", se dedica a ello. En lo que nos interesa, el tratamiento sustantivo de la cuestión se reduce a una exposición de ciertas tácticas de que disponen los abogados que resultan moralmente cuestionables y a las que tienen acceso dado que por lo general las reglas procesales les entregan un margen de discreción que así lo permite. Luego de ello se dedica a cuestionar la fuerza de ciertos argumentos clásicos a favor de la defensa agresiva y celosa. El resultado esperado de considerar ambas exposiciones es el convencimiento de que no hay nada particular o especial en la institución de la defensa penal que nos llame a favorecer la concepción dominante en vez de la alternativa propuesta por Simon.

\footnotetext{
95. Ibídem.

96. Ibíd., pág. 139.
}

Revista de Ciencias Sociales - Número 62 (2013) - Universidad de Valparáíso - ISSN 0716-7725-Valparaíso, Chile 
Respecto de los argumentos que apoyan el estándar de partidismo celoso o la abogacía agresiva del defensor penal, Simon menciona al menos tres, relacionados a la pregunta por la legitimación política de la práctica punitiva estatal y de su legitimación procedimental. Así, menciona por un lado la clásica reclamación libertaria garantista con fundamento en la evitación de la opresión estatal ${ }^{97}$, y por otro lado la naturaleza particular del proceso penal como mecanismo que hace operativa la función expresiva del castigo penal ${ }^{98}$. El punto de estas consideraciones pasa por reconocer la asimetría en las capacidades o recursos con que cuentan los adversarios del proceso penal para enfrentar sus pretensiones de validez, considerando que el Estado ejerce por medio de los persecutores la actividad investigativa y sostiene el monopolio de la acusación penal. La sugerencia libertaria aquí es el empoderamiento del ciudadano que es destinatario de una acusación penal y allí entra el apoyo a la abogacía agresiva a jugar su rol ${ }^{99}$. Simon critica que el peso deba cargarlo la institución de la defensa penal por cuanto ello importa un impedimento en la capacidad del Estado para buscar la condena del culpable sin aportar ninguna protección significativa al inocente, de modo que se aprecie en el diseño de la institución de la persecución penal un balance en términos de los recursos disponibles concordante con la pretensión de satisfacción del estándar de justicia penal, cuya búsqueda implica una tendencia a la condena del culpable y una débil probabilidad de condenar al inocente. En tercer lugar en relación a este fundamento menciona el autor el privilegio contra la autoincriminación que favorece a todo quien preste testimonio (CPP art. 305). Al respecto el autor ofrece dos modos de vincular este principio con el derecho a la defensa: por un lado, puede tratarse simplemente de una manifestación del derecho a guardar silencio (art. 93-g) como garantía que debe ser ejercida por el abogado, en virtud del derecho a la representación (art. 93-b). En el otro extremo, el vínculo se aprecia allí donde funciona como un estándar con el que

\footnotetext{
97. Ibíd., págs. 173-179.

98. Ibíd., pág. 187.

99. Ibíd., pág. 175.
}

Facultad de Derecho y Ciencias Sociales - Universidad de Valparaíso - Chile 
se pretende evitar el sufrimiento de consecuencias adversas para el imputado que puedan afectarle a causa de revelaciones que pueda decidir efectuar el abogado ${ }^{100}$.

En otra dimensión los argumentos a favor del partidismo celoso responden a la filosofía moral subyacente a la concepción garantista del proceso penal, en virtud de la cual la distribución de las cargas públicas debe hacerse de modo equitativo y, en segundo lugar, la afectación de derechos cuya titularidad corresponde al destinatario de la acusación penal no puede rebasar el estándar dado por la dignidad de éste ${ }^{101}$.

Ahora bien, parece lógico que, desglosando los distintos principios que sirven de fundamento a la concepción dominante de la función del abogado en el proceso penal, se desarrolle un espacio propicio para evaluar la capacidad de rendimiento de cada uno en sus propios términos, y se utilice para ello argumentación propia de filosofía moral, política, o teoría del derecho. El verdadero desafío de una propuesta como la concepción contextual de Simon, es el enfrentamiento del carácter distintivo de la institución de la defensa penal. Para proceder a ello, el autor necesita reconocer aquellos mecanismos o prácticas respecto de cuya implementación puede decirse que los abogados gozan de cierta discreción en sentido débil, en la medida en que tenga sentido esta expresión cuando hace referencia a decisiones respecto de ciertos cursos de acción que son más bien opcionales para el agente, y aunque regulados por ciertas normas (y pautas de conducta) puede la aplicación de éstas al caso concreto resultar difícil por un problema de claridad o especificidad en la descripción de la regla, o bien puede ocurrir que dentro de ciertos límites la decisión no pueda ser sometida a revisión por alguna autoridad. Este espacio de acción que se encuentra disponible para el abogado defensor, que incluye, en la descripción de Simon, el uso deliberado y estratégico de ciertos mecanismos que permiten retardar ciertas actuaciones y así manipular a beneficio del cliente los plazos

\footnotetext{
100. Ibíd., pág. 182.

101. Ibíd., págs. 179-181. La mención que hace del ideal de igualdad en estricto rigor se refiere al principio de igual acceso a una defensa judicial de calidad.
}

Revista de Ciencias Sociales - Número 62 (2013) - Universidad de Valparáíso - ISSN 0716-7725-Valparaíso, Chile 
establecidos, el engaño por medio de la presentación de falso testimonio o por medio de la manipulación vía contrainterrogatorio del testimonio de un testigo de la contraparte que se sabe veraz, es decir, con fines puramente estratégicos, y por último la presentación de información confidencial irrelevante pero dañina a la contraparte o a sus testigos. Esta dimensión representa el espectro de problemas, o zonas grises, donde el contraste entre los dos modelos de la abogacía — que se reproduce en nuestra regulación ética a partir del contraste entre los deberes que consagran el art. $2^{\circ}$ del CEP (cuidado de las instituciones) por un lado, y el art. $4^{\circ}$ (defensa empeñosa del cliente) por el otro- se aprecia de modo particularmente nítido.

En algún sentido lo anterior da cuenta del hecho de que la estructura binaria de la función del abogado defensor se transforma en la práctica en una propiedad de ésta. Por esta razón la cuestión ha sido tratada de varias formas en distintos trabajos. Así, por ejemplo, se ha planteado que esta estructura responde a una reproducción de las forma del Estado en relación al ejercicio del poder, que también reconoce dos alternativas, la del "Estado activista" por un lado, y del "Estado reactivo" por el otro ${ }^{102}$. El primero se corresponde a su vez con la idea de Estado perfeccionista en lo relativo al reforzamiento de valores morales, por cuanto se hace referencia con el concepto a un Estado que "declara conocer lo que es bueno y malo para una sociedad y se dedica, por tanto, a la implementación de políticas estatales" ${ }^{103}$. El segundo se corresponde más bien con una forma de liberalismo puramente procedimental, neutral respecto a la adopción de concepciones del bien por parte de los ciudadanos. La primera concepción, a su vez, se corresponde con la idea de representante judicial que proyecta el art. $2^{\circ}$ del $\mathrm{CEP}^{104}$, la segunda, con el estándar del partidismo celoso. El Estado

102. LÓPEZ, Julián: contribución en "Parte III: El rol del abogado en el proceso penal y la defensa del cliente impopular". En: VV.AA. La ética en el nuevo proceso penal, Seminario de extensión, Centro de Documentación Defensoría Penal Pública, Santiago, Chile, 2003, pág. 62.

103. Ídem.

104. Ibíd., pág. 63.

Facultad de Derecho y Ciencias Sociales - Universidad de Valparaíso - Chile 
reactivo necesita asegurar la eficacia de los procedimientos mínimos necesarios para que los ciudadanos persigan sus intereses, múltiples y de diversa índole, en el marco de una comunidad pluralista respecto de los valores. En ese diseño se asume que,

"la lealtad del abogado hacia el cliente [tiene] un mérito intrínseco, porque es la manera a través de la cual se garantiza [al ciudadano] la posibilidad de actuar eficientemente y con igualdad de oportunidades en la defensa de su interés" ${ }^{105}$.

Ahora bien, no resulta complejo comprender el modo en que, en abstracto, se plantea una tensión constante entre los deberes primarios del abogado, hacia la administración de justicia por un lado, y hacia el cliente por el otro, proyectándose en cada caso concepciones de la función que contrastan constantemente. Lo importante de esto es examinar, en concreto, la tensión de orden ético (práctico) que se produce cuando se toman en cuenta los deberes de segundo orden (o bien, deberes concretos) que se deducen del enunciado del deber primario de defensa empeñosa del cliente, o bien se enumeran en los dos primeros títulos de la sección tercera del CEP. En estos cuerpos de normas se consagran algunos deberes cuyo fundamento se encuentra en los principios generales del título preliminar de este código, tanto respecto del deber de defensa empeñosa como del deber de cuidado de la institución de la administración de justicia. Los problemas interesantes comienzan a aparecer cuando se intentan hacer operativas las prohibiciones y mandatos que contienen las siguientes secciones del nuevo código, en particular — sostengo- la sección tercera sobre conducta debida en el proceso, en especial considerando el modelo (vigente desde hace solo una década) procesal penal adversarial chileno.

\section{Bibliografía}

DEERING, Christopher, "Candor towards the tribunal. Should an attorney sacrifice truth and integrity for the sake of the client?", Suffolk U. Law Review, 31, 59, 1997-1998.

105. Ibíd., pág. 64.

Revista de Ciencias Sociales - Número 62 (2013) - Universidad de Valparáíso - ISSN 0716-7725-Valparáiso, Chile 
DERSHOWITZ, Alan, Letters to a young lawyer, Basic Books, 2001.

EVANS, Adrian, Assessing Lawyers' Ethics. A practitioners' guide, Cambridge University Press, New York, 2011.

FRIED, Charles, "The lawyer as friend: The moral foundations of the Lawyer-Client Relation”, The Yale Law Journal, 85,1976.

FUENZALIDA, Pablo, "Notas sobre la jurisdicción ética de los colegios profesionales", Doctrina MJD 200, 2008 (disponible en www.microjuris.cl).

GIEGERICH, Thomas, “The Lawyer's Moral Paradox”, 1979 Duke Law Journal 1335-1358, 1979.

KAUFMAN, Andrew, "Law and ethics", The Hastings Center Report, Vol. 7, $\mathrm{N}^{\circ}$ 6, 1977.

KAUFMAN, Andrew, "A commentary on Pepper". En del mismo, Problems in professional responsibility, Third Edition, Little Brown and Company, Law School Casebook series, 1989.

LEGA, Carlo, Deontología de la profesión de abogado, Traducción de Miguel Sánchez Moron, Madrid, Civitas, 1983

LÓPEZ, Julián, contribución en "Parte III: El rol del abogado en el proceso penal y la defensa del cliente impopular". En La ética

en el nuevo proceso penal, Seminario de extensión, Centro de Documentación Defensoría Penal Pública, Santiago, Chile, 2003.

LUBAN, David, "The lysistratian prerogrative: a response to Stephen Pepper”. En Kaufman, Andrew, Problems in professional responsibility, Third Edition, Little Brown and Company, Law School Casebook series, 1989.

LUBAN, David, "The disengagement of the legal profession: Keller v. State Bar of California”, The Supreme Court Review, Vol. 1990.

MALIANDI, Ricardo, Ética, conceptos y problemas, Buenos Aires, Biblios, 2004

MORGAN, Thomas, ROTUNDA, Ronald, (eds.) Problems and materials on professional responsibility, Sixth edition, The

foundation press Inc., New York, 1955.

PEPPER, Stephen, "A rejoinder to professors Kaufman and Luban", American Bar Foundation research journal, N ${ }^{\circ}$ 4, 1986.

PEPPER, Stephen, "The lawyer's amoral ethical role: a defense, a problem, and some possibilities". En Kaufman, Andrew, Problems

Facultad de Derecho y Ciencias Sociales - Universidad de Valparaíso - Chile 
in professional responsibility, Third Edition, Little Brown and Company, Law School Casebook series, 1989.

SAMPFORD, Charles, PARKER, Christine, "Legal regulation, ethical standard-setting, and institutional design”. En Parker, Sampford, (eds.) Legal ethics and legal practice: contemporary issues, Clarendon Press, Oxford, 1995.

SHAFFER, Thomas, "Legal ethics and the good client", Catholic University Law Review, 36, 319, Winter, 1987.

SILVA BASCUÑÁN, Alejandro, El abogado, un servidor de la justicia, Editorial Jurídica de Chile, Santiago, Chile, 2010.

SIMON, William, The Practice of Justice, Harvard University Press, 2000.

SINGER, Peter, Practical Ethics, Second Edition, Cambridge University Press, 1993.

VÁZQUEZ, Francisco, Ética, deontología y abogados, Barcelona, Eiunsa S.A., 1996.

VILLARROEL, Raúl, (ed.), Ética Aplicada. Perspectivas de responsabilidad para la sociedad civil en un mundo globalizado, "Centro de Estudios de Ética Aplicada” de la Universidad de Chile, Editorial Universitaria Santiago, Chile, 2009.

WASSERSTROM, Richard, "Lawyer as professionals: some moral issues". En Kaufman, Andrew, Problems in professional responsibility, Third Edition, Little Brown and Company, Law School Casebook series, 1989.

WILLIAMS, Bernard, "Professional morality and its dispositions". En del mismo, Making sense of humanity and other philosophical papers, Cambridge University Press, 1995. 